\section{Research Square}

Preprints are preliminary reports that have not undergone peer review.

They should not be considered conclusive, used to inform clinical practice, or referenced by the media as validated information.

\title{
Healthcare Service Utilization Patterns and Patient Experience in Persons With High Healthcare Needs: A Comparison Across 22 Countries
}

Olena Bychkovska ( $\sim$ olena.bychkovska@paraplegie.ch )

Swiss Paraplegic Research

Piotr Tederko

Medical University of Warsaw

Julia Patrick Engkasan

University Malaya Medical Centre

Abderrazak Hajjioui

Sidi Mohamed Ben Abdellah University

Armin Gemperli

Swiss Paraplegic Research

\section{Research Article}

Keywords: Utilization pattern, patient experience, PREMs, primary healthcare, high healthcare needs, spinal cord injury, country comparison

Posted Date: December 9th, 2021

DOI: https://doi.org/10.21203/rs.3.rs-1106862/v1

License: @ (i) This work is licensed under a Creative Commons Attribution 4.0 International License. Read Full License 


\section{Abstract}

\section{Background}

Persons with complex health conditions, e.g. spinal cord injury (SCl), frequently visit numerous clinical settings. Their service utilization and patient experience is a comprehensive indicator of how a system is functioning overall. This study compared the patient experience of persons with chronic SCl in relation to healthcare service utilization patterns in 22 countries, hypothesizing that primary-care oriented patterns would offer better experience.

\section{Methods}

This study was based on International Spinal Cord Injury Survey with 12588 participants from 22 countries worldwide. Utilization clusters were identified by cluster analysis, experience score was attained by partial credit model. The association between the two was explored by regression analysis.

\section{Results}

Highest share of visits was to primary care physician (18\%) and rehabilitation physician (16\%). Utilization patterns had diverse orientation: from primary care to specialized and from inpatient to outpatient. The experience was reported as very good and good across different dimensions: $78 \%$ reported respectful treatment; 75\% - clear explanations; 71\% - involvement in decision making; 63\% - satisfaction with care. Average experience score on 0-100-point scale was 64, highest - 74 (Brazil) and lowest - 52 (Japan, South Korea). Service utilization patterns were associated with patient experience, but no uniformly better patient experience was found for neither primary or specialized care-oriented systems.

\section{Conclusion}

While there are distinct utilization patterns between countries of how persons with chronic $\mathrm{SCl}$ use the healthcare system, neither the more primary care oriented nor the specialized care system leads to a uniformly better patient experience.

\section{Introduction}

The design of healthcare system and healthcare provision models play a key role in obtaining the desirable health outcomes. ${ }^{1}$ It is rather a complex question how to organize the healthcare provision, and even much so for persons with complex health conditions and high healthcare needs. The more severe the condition a person has, the less likely they are to receive comprehensive care ${ }^{2}$, which in a vicious cycle, is leading to worsening of their health condition. ${ }^{3}$

Persons living with spinal cord injury (SCl) utilize numerous clinical settings with high frequency for follow-up treatment of acute secondary health conditions. ${ }^{4}$ Their service utilization and patient experience are a comprehensive indication of how well the health system is functioning, considering that the system is not tailored for this patient group. ${ }^{5}$

The overall objective of this study is to identify the healthcare system most responsive to patient needs across 22 countries by classifying the healthcare utilization pattern of persons with chronic SCl and relating this to the patient experience. Specifically, this cross-sectional study aims to understand: 1) What are the healthcare service utilization patterns among persons living with chronic SCl in different countries? 2) What is the patient experience with healthcare among persons with chronic $\mathrm{SCl}$ in different countries? 3) Is patient experience with healthcare related to healthcare utilization patterns and what care models assure better patient experience? Study hypothesis is that persons with chronic SCl who rely more on primary care report better care experience. Primary care is associated with higher patient satisfaction as it is shown to ensure trust and longitudinal relationship between the doctor and the patient. ${ }^{6-8}$

\section{Methods}

\section{Data collection and sampling}

This study relies on the International Spinal Cord Injury (InSCl) cross-sectional, community-based, questionnaire survey conducted in $2017-2019 .{ }^{9}$ InSCl is the first international survey that aims to describe the lived experience of persons living with chronic $\mathrm{SCl}$ in the community. The survey is part of the International Learning Health System for Spinal Cord Injury Study (LHS-SCI), which is embedded in the World Health Organization's Global Disability Plan. ${ }^{10}$ LHS-SCI was launched in 2017 with the support of the World Health Organization (WHO), the International Society for Physical and Rehabilitation Medicine (ISPRM) and the International Spinal Cord Society (ISCoS). ${ }^{10}$ InSCl covers 22 countries across all WHO regions and was planned to be repeated every five years. The survey's role is to gather data for further analysis leading to policy and practice changes, aimed at strengthening rehabilitation and other services both for persons with $\mathrm{SCl}$ and the general population. ${ }^{11}$

The study population included adults with SCI living in the community across 22 countries: Australia, Brazil, China, France, Germany, Greece, Indonesia, Italy, Japan, Lithuania, Malaysia, Morocco, The Netherlands, Norway, Poland, Romania, South Africa, South Korea, Spain, Switzerland, Thailand, and the USA. The study participants were adults eighteen years old or older with non-traumatic or traumatic SCl. Those receiving first rehabilitation or first acute care during the data collection were excluded from the study due to the lack of experience of living with $\mathrm{SCl}$ in the community. ${ }^{9}$

Each participating country had a national study center that led the questionnaire translation, data collection and adaptation, reminder management etc. Swiss Paraplegic Research in Nottwil, Switzerland, coordinated InSCl and provided recommendations on sampling as well as data collection, storage, and analysis. ${ }^{9}$ Sampling frames were formed from national registries of persons with SCl, from databases of academic or level I trauma hospitals, from clinical records of specialized rehabilitation centers, or from membership registries of organizations for persons with disability or insurance agencies. ${ }^{9}$ The 125 -item 
questionnaire had different data collection options, depending on the country, including paper-pencil or online questionnaire, telephone or face-to-face interviews. Each country obtained ethical approval for conducting the survey and informed consent was signed by each study participant or participant's authorized representative. Collected data were de-identified and stored in a secure central database. ${ }^{9}$

In this study, we measure experience through Patient Reported Experience Measures (PREMs), which represent the perception of a personal experience of the received healthcare. ${ }^{12,13}$

\section{Data analysis and management}

By means of an unsupervised cluster analysis, countries' health systems were classified with regards to healthcare service utilization among persons with SCl. Cluster analysis was based on the visits to 12 types of health providers and the number of hospitals stays, in the last 12 months before completing the survey. For each country, the relative share in percentage of visits to each provider, or of no visit to any provider, were computed, as well as the percentage of individuals with no, one, two or more than three inpatient hospitalizations. Hierarchical cluster analysis was conducted on a dissimilarity matrix based on Gower distance and Ward's methods linkage.

Experience while receiving healthcare services was measured by four five-point Likert scale survey questions on: respectful treatment; clear explanations; involvement in decision making; satisfaction with healthcare. A partial credit model was applied to attain an interval-scaled experience (PREM) score for each individual, which were scaled to a 0-100 range. The experience scores were then averaged per country. The partial credit model assumptions were tested by checking ordered categories via graphs; local independence test; differential item functioning tested on the different characteristics (sex, age, SCI type, and SCI degree); unidimensionality test though running principal component analysis and factor analysis on polychoric correlations.

The association of PREM score as a dependent variable with utilization cluster as independent variable was explored by means of univariate and multivariable regression analysis. We adjusted by the nonmodifiable socio-demographic (sex, age, migration background) and spinal cord injury characteristics (tetra- or paraplegia, complete or incomplete lesion, traumatic or nontraumatic etiology, years lived with injury). All statistical analyses were conducted using Stata 16.

\section{Results}

\section{Socio-demographic characteristics of study participants}

The survey was conducted among 12588 participants, as three participants had to be deleted from the study after a data quality check. The response rates were only available for countries with predefined sample frames and are the following: South Africa $54 \%$, Norway $42 \%$, Switzerland $39 \%$, Netherlands $33 \%$, Germany $32 \%$, Poland $32 \%$, Australia $27 \%$, China $23 \% .{ }^{14}$ The sample was predominantly male $(73 \%)$, with an average age of 51 years, mostly without migrant background ( $91 \%)$ and living with others (77\%). The majority of the participants had paraplegia (61\%) for 13 years on average with incomplete lesion (60\%) and traumatic etiology $(80 \%)$ (Table 2).

\section{Healthcare utilization}

The healthcare providers with highest share of visits in the last 12 months were primary care physician (share of $18 \%$ among all healthcare providers) and physical and rehabilitation medicine (PRM)/SCI physician (16\%), followed by other specialist physicians (11\%) and physiotherapist (13\%) (Table 1). The chiropractor had the smallest share (1\%) among the 12 providers. Across all countries, $26 \%$ of patients visited only one healthcare provider. Two, three, four, five, six or seven providers were visited by $13 \%, 13 \%, 12 \%, 11 \%, 9 \%$ and $6 \%$ of individuals, respectively. Less than $5 \%$ visited eight or more providers. $34 \%$ did not visit any healthcare provider in the last 12 months. More than half of respondent (54\%) did not have any inpatient stays in the last 12 months. $19 \%$ had one stay, $9 \%$ had two and another $9 \%$ had three or more stays.

\section{Healthcare utilization cluster characteristics}

Nine service utilization clusters were identified with unsupervised cluster analysis (Table 1). Cluster 4 (China) had the lowest service visits across many services, while Cluster 7 (Brazil) featured the highest and most diverse use of services.

Cluster 1 (Australia, South Africa, USA): System with many visits and almost equal reliance on primary and specialized care. General practitioner (GP) services were used slightly more than PRM physician/SCl specialist services. Home workers, chiropractors, or occupational therapists were frequently visited. Inpatient stays were slightly higher than the overall average.

Cluster 2 (Japan, South Korea): System with a strong reliance on SCI specialized outpatient care. Countries with bigger share of visits to a PRM physician/SCI specialist (23\%), and to other specialized physicians (14\%) than to a GP (9\%). Dentists were slightly more visited compared to other clusters (9\%), while visits to psychologists were among the lowest (1\%). A majority (52\%) of patients in this cluster had no inpatient stays.

Cluster 3 (Switzerland, Germany, Lithuania, Norway, The Netherlands): Primary care-oriented system with almost equal use of specialized services. This cluster had the second highest share of GP visits (22\%) after Cluster 6 (Indonesia, Poland) (26\%). The use of PRM physician/SCI specialist services ( $9 \%$ ) was lower than use of GPs (22\%), yet other specialist physicians were often visited (12\%). Percentage of dentist visits was the highest among all clusters (15\%), while the use of nursing services was the lowest (4\%).

Cluster 4 (China): System with low healthcare service utilization and reliance mostly on SCl specialized outpatient care, with some consideration of complementary and alternative medicine. This cluster had the largest percentage of those that indicated not visiting any healthcare provider (34\%). Similar to 
Cluster 2 (Japan, South Korea), this cluster had an almost twice as large share of visits to a SCl specialist (23\%) than to a GP (12\%). It had low attendance across multiple services: dentist ( $1 \%)$, home healthcare worker $(0 \%)$, psychologist $(0 \%)$ and occupational therapist $(0 \%)$. On the other hand, the share of visits to chiropractor (3\%) and alternative medicine specialist (3\%) was the largest among all clusters.

Cluster 5 (France, Greece, Italy, Morocco, Spain): System with similar use of primary and specialized services and moderate number of inpatient stays. The patients in these countries had almost equal (18\% vs. 16\%) shares of visits to GP and PRM specialists. Attendance of occupational therapist is among the lowest (1\%) and pharmacist services (13\%) was higher than in other clusters.

Cluster 6 (Indonesia, Poland): Primary care-oriented system with infrequent visits. Among the countries in this cluster, the number of persons with no visits to any healthcare provider (10\%) was almost three times higher than the average across all clusters. GP services had the highest share across all clusters (26\%), along with the nurse or midwife services (12\%). Inpatient stays were similar to the overall cluster average.

Cluster 7 (Brazil): Generally specialized system with frequent visits and hospital stays. This cluster had the lowest percentage of persons without any visit to a healthcare provider (0.3\%). The share of visits to the PRM physician was high (19\%) and visits to a physiotherapist was the highest among all clusters (19\%). Persons in this cluster frequently used diverse services such as an occupational therapist, chiropractor, physiotherapist and psychologist. One third of respondents in this cluster had one hospital stay. The cluster had the lowest percentage of three or more hospital stays among all clusters (4\%).

Cluster 8 (Malaysia, Thailand): Inpatient-oriented SCI specialized system. In this cluster the share of SCl specialist visits (28\%) was twice as large as those to the GP $(11 \%)$. Hospitalizations were above the cluster average. Alternative medical specialist services were frequently used (5\%) while pharmacist services were the least used among all clusters $(6 \%)$.

Cluster 9 (Romania): Inpatient-oriented care system with highest number of hospitalizations. This cluster had the lowest number of persons without any hospital stay (23\%), almost half of the share less than the cluster with second lowest stays (Cluster 8$)$. The percentage of persons with two (28\%) and three or more (30\%) hospital stays was almost three times higher than the overall cluster average. The percentage of visits to GP, PRM physician/SCl specialist, and physiotherapist was similar $(19 \%, 17 \%$ and $17 \%)$. Services of pharmacists $(13 \%)$ and occupational therapists (7\%) were frequently utilized.

\section{Socio-demographic characteristics of the healthcare utilization clusters}

The highest percentage of males was in Cluster 6 (Indonesia, Poland) (80\%) and 7 (Brazil) (79\%). Mean age was the lowest in Cluster 9 (Romania) (38 years) and highest in Cluster 3 (Switzerland, Germany, Lithuania, Norway, The Netherlands) (56 years). The percentage of respondents with an immigrant background was below $1 \%$ in most clusters, with larger shares in Cluster 1 (Australia, South Africa, USA) (19\%), Cluster 3 (Switzerland, Germany, Lithuania, Norway, The Netherlands) (11\%), and Cluster 5 (France, Greece, Italy, Morocco, Spain) (6\%). The percentage of participants with tetraplegia was highest in Cluster 2 (Japan, South Korea) (42\%), followed by Clusters 7 (Brazil) (40\%) and 6 (China) (40\%). In other clusters this percentage was between $31 \%$ and $38 \%$. Cluster 4 (China) and Cluster 7 (Brazil) had the highest percentage of those with incomplete lesion, $75 \%$ and $79 \%$ respectively. This percentage was lowest in Cluster 2 (Japan, South Korea) (40\%). The percentage of those with nontraumatic etiology was highest (32\% and $30 \%)$ in Cluster 4 (China) and Cluster 7 (Brazil), and lowest in Cluster 2 (Japan, South Korea) (8\%).

\section{Experience with healthcare system}

The majority of the responders rated their healthcare experience as good or very good across all countries and all four experience categories: respectful treatment $84 \%$; clear explanations $81 \%$; involvement in decision making $77 \%$; satisfaction with healthcare $65 \%$. A small fraction of responders rated their healthcare experience as bad (respectful treatment $3 \%$; clear explanations $4 \%$; involvement in decision making $4 \%$; satisfaction with healthcare $9 \%$ ) or very bad (respectful treatment 1\%; clear explanations 1\%; involvement in decision making $2 \%$; satisfaction with healthcare $3 \%$ ). In terms of overall experience (PREM score (0-100)) by country, the lowest scores were attained by Morocco (44), followed by South Korea (49), Lithuania (55), China (55), Poland (57) and Italy (57). The highest country experience scores were observed in the USA (78), Spain (77), Brazil (74), Australia (73), Malaysia (72) and Switzerland (71). The average experience score across all healthcare utilization clusters was 64 (Table 2). The highest cluster score was 74 in Cluster 7 (Brazil) and the lowest was 52 in Cluster 2 (Japan, South Korea). There was a wide variability of PREM scores within the clusters: the difference among the individual country's experience scores was 33 points between countries in Cluster 5 (France, Greece, Italy, Morocco, Spain), 16 in Cluster 3 (Switzerland, Germany, Lithuania, Norway, The Netherlands), 13 in cluster 1 (Australia, South Africa, USA), 12 in Cluster 2 (Japan, South Korea), 5 in Cluster 6 (Indonesia, Poland), and 3 in Cluster 8 (Malaysia, Thailand).

Utilization type was associated with patient experience (Figure 1). The associations did not significantly differ when unadjusted (with 12588 observations) or adjusted (with 11838 observations) for socio-demographic and SCI lesion characteristics. Persons of age $46-60$ years and those older than 76 had PREM score higher by 2.2 and 2.3 than those younger than 30 years, while for persons aged 61-75 years this score was 3.9 points higher. Living with tetraplegia was associated with having 1.2 points lower PREM score than living with paraplegia. Those with incomplete lesion had a 1.6 points higher experience score than those with complete lesion. Other characteristics such as sex, migration background, injury etiology, and time since injury showed no association with PREM score (Supplementary Table 1).

\section{Discussion}

This study classified 22 healthcare systems from the perspective of individuals with chronic SCl, by quantifying how follow-up healthcare services were actually used. Nine clusters of utilization patterns were identified. These clusters were then associated with the care experience to identify better and worse performing systems in terms of patient experience. While there is a difference in patient experience among the utilization clusters, contradictory to our hypothesis, neither the more primary care oriented nor the specialized care systems led to a uniformly superior patient experience. The specific aspects of 
patient experience that this study measured (decision involvement, respectful treatment, clear explanations, satisfaction) seems equally achieved by primary and specialized care alike.

Regarding the healthcare utilization patterns, our finding that persons with chronic spinal cord injury frequently use various follow-up healthcare services across different healthcare settings is supported by the literature. ${ }^{15,4,16,17}$ Although persons with complex health conditions have greater difficulties accessing care in general, including specialized care and rehabilitation, ${ }^{16}$ those with high and complex healthcare needs - including persons with $\mathrm{SCl}-$ have a higher likelihood of doctor visits. ${ }^{4}$ These findings are particularly evident in certain countries with high frequency of use of different services (e.g., Australia, South Africa, USA (Cluster 1); Brazil (Cluster 7)) and high frequency of inpatient stays (e.g., Malaysia and Thailand (Cluster 8); Romania (Cluster 9)).

As for the association between the utilization cluster and the patient experience, it was found that different utilization patterns led to similar experience. Hence, longitudinal relationship and trust between the healthcare provider and the patient, which is shown to be established in primary care and lead to higher satisfaction, ${ }^{6-8}$ in persons with $\mathrm{SCl}$ might also be equally associated with specialized care. Similarly to the literature, our findings on utilization suggest that often persons with a complex conditions have to use complementary specialist services. ${ }^{18}$ Especially the $\mathrm{SCl}$ management is often being redirected to specialized care, emergency and inpatient stays. ${ }^{15,19,20}$ This could mean that gatekeeping may not be functioning for those with a complex medical conditions, such as SCl. ${ }^{21,22}$ While the gatekeeping's role of primary care is to assure the right allocation of resources with cost containment and improved health, ${ }^{21}$ it remains unclear if that goal is achieved. Primary care services may not be prepared enough for persons with SCl, while emergency and inpatient stays are not ideal for prevention and follow-up management of preventable conditions. ${ }^{23}$

Although it has been established that healthcare in high-income countries is often better performing than in low-income countries, ${ }^{10,16,24}$ this view was not supported by our study for persons with chronic SCI. For example, Brazil (Cluster 7) showed the highest patient experience score, while Japan and South Korea (Cluster 2) showed the lowest. Despite healthcare systems generally being viewed as one single structure and equated with the country's boundaries, healthcare may in reality be fragmented and differ geographically and personally. ${ }^{23}, 25$ The difference may also stem from the fact that in this study we focus on one indicator, namely patient experience score, based on interaction with the healthcare provider.

This study focused on the perspective of individuals with SCl from numerous countries with diverse characteristics, including high-, middle- and low-income countries from all WHO regions of the world. Besides its strengths, this study had some limitations. Firstly, the sampling setting and strategy may have affected the identified utilization types. In addition, in certain participating countries, the sampling setting was limited to rehabilitation facilities (Brazil, Germany, Netherland, Norway), acute or general hospitals (China, Spain). This selection may have resulted in more specialized care oriented utilization types. ${ }^{9}$ It remains unclear if certain countries showed higher use of specialized services because of such overall system orientation for the entire population, with specifically persons with $\mathrm{SCl}$ in those countries directed to specialists ${ }^{22}$, or due to our survey sampling setting oriented on specialized care in those countries ${ }^{9}$. The sampling frames in most countries covered only a certain region and do not represent the entire country. Secondly, data collection methods (e.g., interview vs. survey) altered among participating countries ${ }^{9}$, which could have led to a potential bias. Thirdly, we only controlled for the nonmodifiable factors in the regression analysis, while there could be other potential factors influencing patient experience.

\section{Conclusion}

While there are distinct patterns between countries on how persons with chronic SCI navigate the healthcare system, neither the more primary care oriented nor the specialized care system leads to a uniformly better patient experience.

\section{Abbreviations}

SCl: Spinal Cord Injury; InSCl: International Spinal Cord Injury Survey; LHS-SCI: International Learning Health System for Spinal Cord Injury Study; WHO: World Health Organization; ISPRM: International Society for Physical and Rehabilitation Medicine; ISCoS: International Spinal Cord Society; PREMs: Patient Reported Experience Measures;

PRM: Physical and Rehabilitation Medicine; GP: General Practitioner.

\section{Declarations}

\section{Ethics approval and consent to participate}

Ethical approval was granted in each participating country based on their regulations. Each study participant signed an informed consent form. The InSCl Study Group approved the present study based on its protocol.

\section{Consent for publication}

Not applicable.

\section{Availability of data and materials}

The data that support the findings of this study are available from InSCI Study Group but restrictions apply to the availability of these data, which were used under license for the current study, and so are not publicly available. Data are however available from the authors upon reasonable request and with permission of InSCl Study Group. 


\section{Competing interest}

The authors declare no competing interest relevant to this article.

\section{Funding}

This project has received funding from the European Union's Horizon 2020 Research and Innovation Program under the Marie Skłodowska-Curie grant agreement No 801076, through the SSPH+ Global PhD Fellowship Program in Public Health Sciences (GlobalP3HS) of the Swiss School of Public Health.

The other funds were provided by Swiss Paraplegic Research to fund two of the research positions of authors (OB, AG).

\section{Authors' contributions}

Study conceptualization and development: OB and AG, reviewed and supplemented by PT, JPE, and AH. Methodology: OB and AG, reviewed and supplemented by PT, JPE, and AH. Data analysis and interpretation: OB in supervision by AG. Writing: OB in supervision by AG, reviewed and supplemented by PT, JPE, and AH. All the authors have read and approved the final draft of the manuscript.

\section{Acknowledgements}

This study relies on the International Spinal Cord Injury Survey (InSCI). The survey is part of the International Learning Health System for Spinal Cord Injury Study (LHS-SCI), which is embedded in the World Health Organization's Global Disability Plan. LHS-SCl was launched in 2017 with the support of the World Health Organization (WHO), the International Society for Physical and Rehabilitation Medicine (ISPRM) and the International Spinal Cord Society (ISCoS).

The members of the InSCI Steering Committee are: Julia Patrick Engkasan (ISPRM representative), James Middleton (ISCoS representative; Member Scientific Committee; Australia), Gerold Stucki (Chair Scientific Committee), Mirjam Brach (Representative Coordinating Institute), Jerome Bickenbach (Member Scientific Committee), Christine Fekete (Member Scientific Committee), Christine Thyrian (Representative Study Center), Linamara Battistella (Brazil), Jianan Li (China), Brigitte Perrouin-Verbe (France), Christoph Gutenbrunner (Member Scientific Committee; Germany), Christina-Anastasia Rapidi (Greece), Luh Karunia Wahyuni (Indonesia), Mauro Zampolini (Italy), Eiichi Saitoh (Japan), Bum Suk Lee (Korea), Alvydas Juocevicius (Lithuania), Nazirah Hasnan (Malaysia), Abderrazak Hajjioui (Morocco), Marcel W.M. Post (Member Scientific Committee; The Netherlands), Johan K. Stanghelle (Norway), Piotr Tederko (Poland), Daiana Popa (Romania), Conran Joseph (South Africa), Mercè Avellanet (Spain), Michael Baumberger (Switzerland), Apichana Kovindha (Thailand), Reuben Escorpizo (Member Scientific Committee, USA).

We would like to recognize the contribution of persons with SCl to the study and thank them for participation and sharing their experience in the InSCl survey.

\section{Authors' details}

Olena Bychkovska ${ }^{1,2}$, Piotr Tederko ${ }^{3}$, Julia Patrick Engkasan ${ }^{4}$, Abderrazak Hajjioui ${ }^{5}$, Armin Gemperli ${ }^{1,2,6}$

1. Department of Health Sciences and Medicine, University of Lucerne, 6002 Lucerne, Switzerland

2. Swiss Paraplegic Research, 6207 Nottwil, Switzerland

3. Department of Rehabilitation, Medical University of Warsaw, 02637 Warsaw, Poland

4. Department of Rehabilitation Medicine, University Malaya Medical Centre, 50603 Kuala Lumpur, Malaysia

5. Faculty of Medicine and Pharmacy, Sidi Mohamed Ben Abdellah University, 1975 Fes, Morocco

6. Center for Primary and Community Care, University of Lucerne, 6002 Lucerne, Switzerland

\section{Authors' information}

Olena Bychkovska is a Ph.D. student in Swiss Paraplegic Research, and University of Lucerne, Department of Health Sciences and Medicine, Switzerland, and fellow of Marie Skłodowska-Curie and Swiss School of Public Health Global Fellowship Program.

Piotr Tederko is a Professor in Medical University of Warsaw, Department of Rehabilitation, Poland and Deputy Secretary to the European Board of Physical and Rehabilitation Medicine.

Julia Patrick Engkasan is an Associate Professor in University Malaya Medical Centre, Department of Rehabilitation Medicine, Malaysia.

Abderrazak Hajjioui is a Professor in Sidi Mohammed Ben Abdellah University, Faculty of Medicine and Pharmacy, and Consultant and Head of Physical and Rehabilitation Medicine Department, University Hospital Hassan II Fes, Morocco.

Armin Gemperli is a Professor in Swiss Paraplegic Research, and University of Lucerne, Department of Health Sciences and Medicine, Switzerland.

\section{References}


1. Kruk ME, Gage AD, Arsenault C, Jordan K, Leslie HH, Roder-DeWan S, et al. High-quality health systems in the Sustainable Development Goals era: time for a revolution. The Lancet Global Health. 2018;6(11):e1196-e252.

2. McColl MA, Aiken A, Schaub M. Do people with disabilities have difficulty finding a family physician? International Journal of Environmental Research and Public Health. 2015;12(5):4638-51.

3. Dejong G, Palsbo SE, Beatty PW, Jones GC, Knoll T, Neri MT. The organization and financing of health services for persons with disabilities. The Milbank Quarterly. 2002;80(2):261-301.

4. Dryden DM, Saunders LD, Rowe BH, May LA, Yiannakoulias N, Svenson LW, et al. Utilization of health services following spinal cord injury: a 6-year followup study. Spinal Cord. 2004;42(9):513-25.

5. Bickenbach J, Officer A, Shakespeare T, von Groote P, World Health Organization, The International Spinal Cord Society. International perspectives on spinal cord injury / edited by Jerome Bickenbach, et al. World Health Organization. 2013.

6. Chen W, Feng Y, Fang J, Wu J, Huang X, Wang X, et al. Effect of trust in primary care physicians on patient satisfaction: a cross-sectional study among patients with hypertension in rural China. BMC Family Practice. 2020;21(1):196.

7. OECD. Realising the potential of primary health care. OECD Publishing. 2020.

8. Platonova EA, Kennedy KN, Shewchuk RM. Understanding patient satisfaction, trust, and loyalty to primary care physicians. Medical Care Research and Review. 2008;65(6):696-712.

9. Gross M, Post M, Ehrmann-Bostan C, Fekete C, Hasnan N, Middleton J, et al. Study protocol of the International Spinal Cord Injury (InSCI) Community Survey. American Journal of Physical Medicine \& Rehabilitation. 2017;96:S23-S34.

10. Bickenbach J, Batistella L, Gutenbrunner C, Middleton J, Post MW, Stucki G. The International Spinal Cord Injury Survey: the way forward. Archives of Physical Medicine and Rehabilitation. 2020;101(12):2227-32.

11. Zampolini M, Stucki G, Giustini A, Negrini S. The individual rehabilitation project: a model to strengthen clinical rehabilitation in health systems worldwide. European Journal of Physical and Rehabilitation Medicine. 2019;56(1):1-4.

12. Hodson M, Andrew S, Michael Roberts C. Towards an understanding of PREMS and PROMS in COPD. Breathe. 2013;9(5):358-64.

13. Male L, Noble A, Atkinson J, Marson T. Measuring patient experience: a systematic review to evaluate psychometric properties of patient reported experience measures (PREMs) for emergency care service provision. International Journal for Quality in Health Care: Journal of the International Society for Quality in Health Care. 2017;29(3):314-26.

14. Fekete C, Brach M, Ehrmann C, Post MWM, Middleton J, Battistella L, et al. Cohort profile of the International Spinal Cord Injury Community Survey implemented in 22 countries. Archives of Physical Medicine and Rehabilitation. 2020;101(12):2103-11.

15. Ho CH. Primary care for persons with spinal cord injury - not a novel idea but still under-developed. The Journal of Spinal Cord Medicine. 2016;39(5):5003.

16. Beatty PW, Hagglund KJ, Neri MT, Dhont KR, Clark MJ, Hilton SA. Access to health care services among people with chronic or disabling conditions: patterns and predictors. Archives of Physical Medicine and Rehabilitation. 2003;84(10):1417-25.

17. McColl. Disability studies at the population level: issues of health service utilization. American Journal of Occupational Therapy. 2005;59(5):516-26.

18. Blumenthal D, Mort E, Edwards J. The efficacy of primary care for vulnerable population groups. Health Services Research. 1995;30(1 Pt 2):253-73.

19. Cox RJ, Amsters DI, Pershouse KJ. The need for a multidisciplinary outreach service for people with spinal cord injury living in the community. Clinical Rehabilitation. 2001;15(6):600-6.

20. McColl MA, Aiken A, McColl A, Sakakibara B, Smith K. Primary care of people with spinal cord injury: scoping review. Canadian Family Physician. 2012;58(11):1207-16, e626-35.

21. Reibling N, Wendt C. Access regulation and utilization of healthcare services. The Mannheim Centre for European Social Research. 2008.

22. Milligan J, Lee J, Hillier LM, Slonim K, Craven C. Improving primary care for persons with spinal cord injury: Development of a toolkit to guide care. Journal of Spinal Cord Medicine. 2020;43(3):364-73.

23. Schäfer WL, Boerma WG, Kringos DS, De Maeseneer J, Greß S, Heinemann S, et al. QUALICOPC, a multi-country study evaluating quality, costs and equity in primary care. BMC Family Practice. 2011;12(1):115.

24. Hamilton R, Driver S, Noorani S, Callender L, Bennett M, Monden K. Utilization and access to healthcare services among community-dwelling people living with spinal cord injury. Journal of Spinal Cord Medicine. 2017;40(3):321-8.

25. OECD. Geographic variations in health care: what do we now and what can be done to improve health system performance? OECD Health Policy Studies. OECD Publishing. 2014.

\section{Tables}

Table 1. Utilization of Healthcare Services during 12 Months

\section{Table 2. Utilization Clusters Characteristics}

\section{Figures}


Clusters

\begin{tabular}{|c|c|c|c|c|c|c|c|c|c|c|c|}
\hline & & & \multicolumn{2}{|l|}{1} & \multicolumn{2}{|l|}{2} & \multicolumn{2}{|l|}{3} & 4 & \multicolumn{2}{|l|}{5} \\
\hline & \multicolumn{2}{|l|}{ Total } & \multicolumn{2}{|c|}{$\mathrm{AU}, \mathrm{ZA}, \mathrm{US}^{\mathrm{a}}$} & \multicolumn{2}{|c|}{$J P, K^{a}$} & \multicolumn{2}{|c|}{$\mathrm{CH}, \mathrm{DE}, \mathrm{LT}$, } & $\mathrm{CN}^{\mathrm{a}}$ & \multicolumn{2}{|c|}{ FR, GR, IT, } \\
\hline & Mean & Min/ & Mean & Min/ & Mean & Min/ & Mean & Min/ & Mean & Mean & Min/ \\
\hline & & Max & & Max & & Max & & Max & & & Max \\
\hline $\begin{array}{l}\text { No visits to } \\
\text { ny provider, \% }\end{array}$ & 3.9 & $0.1 / 33.6$ & 1.6 & $0.5 / 3.1$ & 3.0 & $0.7 / 5.3$ & 0.5 & $0.2 / 1.0$ & 33.6 & 2.3 & $0.1 / 5.2$ \\
\hline
\end{tabular}

\begin{tabular}{|c|c|c|c|c|c|c|c|c|c|c|c|}
\hline $\begin{array}{l}\text { Primary care } \\
\text { physician / GP }\end{array}$ & 17.8 & $8.5 / 31.4$ & 17.3 & 16.3/18.8 & 9.4 & $8.5 / 10.3$ & 22.3 & $17.4 / 31.4$ & 12.0 & 17.5 & $12.2 / 23.7$ \\
\hline $\begin{array}{l}\mathrm{PRM}^{\mathrm{b}} / \mathrm{SCl} \\
\text { physician }\end{array}$ & 15.5 & $7.0 / 28.2$ & 12.5 & $8.1 / 16.5$ & 22.6 & $17.6 / 27.6$ & 8.6 & 7.0/10.1 & 23.1 & 16.0 & $13.4 / 17.9$ \\
\hline $\begin{array}{l}\text { Other } \\
\text { specialist } \\
\text { physician }\end{array}$ & 11.3 & $4.0 / 22.2$ & 8.9 & $5.6 / 11.8$ & 14.1 & $12.3 / 15.9$ & 12.1 & $11.5 / 12.9$ & 4.0 & 13.4 & $9.4 / 22.2$ \\
\hline $\begin{array}{l}\text { Nurse of } \\
\text { midwife }\end{array}$ & 6.8 & $1.2 / 12.5$ & 7.5 & $5.4 / 9.5$ & 7.6 & $3.5 / 11.7$ & 3.8 & $1.2 / 4.6$ & 5.7 & 7.0 & $4.7 / 9.3$ \\
\hline Dentist & 8.4 & $0.6 / 16.6$ & 8.6 & $4.8 / 11.8$ & 9.1 & 7.6/10.6 & 14.8 & $12.9 / 16.6$ & 0.6 & 7.5 & $4.2 / 9.9$ \\
\hline Physiotherapist & 12.9 & $6.6 / 19.3$ & 11.3 & $10.1 / 12.2$ & 11.8 & $11.2 / 12.4$ & 14.1 & $11.0 / 16.2$ & 6.6 & 13.0 & $10.3 / 15.2$ \\
\hline Chiropractor & 0.7 & $0.0 / 2.8$ & 1.5 & $0.2 / 2.5$ & 0.7 & $0.6 / 0.7$ & 0.6 & $0.0 / 1.2$ & 2.8 & 0.8 & $0.2 / 1.2$ \\
\hline $\begin{array}{l}\text { Occupational } \\
\text { therapist }\end{array}$ & 4.6 & $0.0 / 10.5$ & 7.4 & $5.6 / 8.8$ & 5.4 & $4.2 / 6.6$ & 5.0 & $3.3 / 6.7$ & 0.0 & 1.3 & $0.9 / 1.8$ \\
\hline Psychologist & 2.8 & $0.2 / 10.6$ & 3.1 & $2.7 / 3.8$ & 0.7 & $0.4 / 1.1$ & 2.6 & $2.1 / 3.2$ & 0.2 & 2.7 & $1.6 / 13.7$ \\
\hline $\begin{array}{l}\text { Alternative } \\
\text { therapist }\end{array}$ & 2.4 & $0.8 / 6.6$ & 2.0 & $1.3 / 2.6$ & 2.2 & $1.6 / 2.9$ & 2.7 & $1.6 / 3.3$ & 3.4 & 1.8 & $1.0 / 3.8$ \\
\hline Pharmacist & 8.9 & $0.4 / 15.0$ & 11.6 & $9.6 / 12.6$ & 7.7 & $7.5 / 8.0$ & 7.5 & $1.4 / 15.0$ & 7.9 & 13.4 & $10.2 / 15.0$ \\
\hline $\begin{array}{l}\text { Home health } \\
\text { care worker }\end{array}$ & 4.0 & $0.0 / 7.8$ & 6.8 & $6.0 / 7.5$ & 5.9 & $5.5 / 6.3$ & 5.4 & $2.6 / 7.8$ & 0.0 & 3.3 & $0.6 / 4.6$ \\
\hline
\end{tabular}

\begin{tabular}{|c|c|c|c|c|c|c|c|c|c|c|c|}
\hline $\begin{array}{l}\text { Number of } \\
\text { inpatient } \\
\text { stays }^{C}, \%\end{array}$ & & & & & & & & & & & \\
\hline 0 stays & 53.7 & $23.2 / 74.8$ & 54.9 & $50.1 / 58.0$ & 51.8 & $49.0 / 54.6$ & 55.2 & $38.8 / 68.5$ & 65.0 & 57.9 & $41.7 / 74.8$ \\
\hline 1 stay & 19.3 & $11.5 / 33.3$ & 15.5 & $11.5 / 19.3$ & 16.7 & $15.6 / 17.9$ & 19.5 & $13.5 / 26.9$ & 19.0 & 18.4 & $13.6 / 25.2$ \\
\hline 2 stays & 8.9 & $4.3 / 27.8$ & 9.2 & $6.0 / 11.8$ & 5.3 & $4.9 / 5.6$ & 7.3 & $4.3 / 9.7$ & 6.7 & 8.2 & $5.8 / 10.3$ \\
\hline $\begin{array}{l}3 \text { and more } \\
\text { stays }\end{array}$ & 8.9 & $0.5 / 30.1$ & 13.6 & $10.8 / 18.0$ & 7.6 & $6.6 / 8.7$ & 7.6 & $2.6 / 12.5$ & 9.2 & 5.4 & $0.5 / 12.4$ \\
\hline
\end{tabular}

a AU - Australia, BR - Brazil, CN - China, FR - France, DE - Germany, GR - Greece, ID - Indonesia, IT - Italy, JP - Japan, LT - Lithuania, MY - Malaysia, M، Romania, ZA - South Africa, KR - South Korea, ES - Spain, CH - Switzerland, TH - Thailand, US - USA

${ }^{b}$ PRM - physical and rehabilitation medicine

${ }^{c}$ Missing values: total: $9.2 \%$, (Cluster) 1: $6.8 \%, 2: 18.6 \%, 3: 10.4 \%, 4: 0.1 \%, 5: 10.1 \%, 6: 9.7 \%, 7: 0 \%, 8: 10 \%, 9: 2.2 \%$ 


\begin{tabular}{|c|c|c|c|c|c|c|c|c|c|c|}
\hline Clusters & & 1 & 2 & 3 & 4 & 5 & 6 & 7 & 8 & 9 \\
\hline Countries & Total & $\begin{array}{l}\mathrm{AU}, \\
\mathrm{ZA} \\
\mathrm{US}^{\mathrm{a}}\end{array}$ & $\begin{array}{l}\mathrm{JP} \\
\mathrm{KR}^{\mathrm{a}}\end{array}$ & $\begin{array}{l}\mathrm{CH}, \mathrm{DE}, \\
\mathrm{LT}, \\
\mathrm{NL}, \mathrm{NO}^{\mathrm{a}}\end{array}$ & $\mathrm{CN}^{\mathrm{a}}$ & $\begin{array}{l}\text { FR, } \\
\text { GR, } \\
I T, \\
\text { MA, } \\
\text { ES }^{a}\end{array}$ & $\begin{array}{l}\text { ID, } \\
\mathrm{PL}^{\mathrm{a}}\end{array}$ & $\mathrm{BR}^{\mathrm{a}}$ & $\begin{array}{l}\mathrm{MY} \\
\mathrm{TH}^{\mathrm{a}}\end{array}$ & $\mathrm{RO}^{\mathrm{a}}$ \\
\hline $\begin{array}{l}\text { PREMs score, } \\
0-100^{b}\end{array}$ & 64 & $\begin{array}{l}72 \\
\text { (AU: } \\
73, \\
\text { SA: } \\
65, \\
\text { US: } \\
78)\end{array}$ & $\begin{array}{l}52 \\
\text { (JA: } \\
61, \\
\text { SK: } \\
49)\end{array}$ & $\begin{array}{l}67 \text { (CH: } \\
71, \\
\text { GER:64, } \\
\text { LN: 55, } \\
\text { NL: 70, } \\
\text { NO: 69) }\end{array}$ & 55 & $\begin{array}{l}62 \\
\text { (FR: } \\
70, \\
\text { GR: } \\
58, \\
\text { IT: } \\
57, \\
\\
\text { MA: } \\
44, \\
\text { SP: } \\
77 \text { ) }\end{array}$ & $\begin{array}{l}58 \\
(\mathrm{IN}: \\
62, \\
\mathrm{PL}: \\
57)\end{array}$ & 74 & $\begin{array}{l}70 \\
\text { (MY: } \\
72, \\
\text { TH: } \\
69)\end{array}$ & 60 \\
\hline
\end{tabular}

\begin{tabular}{|c|c|c|c|c|c|c|c|c|c|c|}
\hline $\begin{array}{l}\text { Male - \% } \\
\text { (Min, Max) }\end{array}$ & $\begin{array}{l}72.8 \\
(58.1, \\
83.1)\end{array}$ & $\begin{array}{l}71.9 \\
(58.1 \\
74.9)\end{array}$ & $\begin{array}{l}77.2 \\
(75.6 \\
82.1)\end{array}$ & $\begin{array}{l}70.1 \\
(62.8, \\
71.2)\end{array}$ & 71.1 & $\begin{array}{l}72.1 \\
(69.8 \\
74.3)\end{array}$ & $\begin{array}{l}80.4 \\
(67.2 \\
83.1)\end{array}$ & 79.1 & $\begin{array}{l}74.9 \\
(70.9 \\
79.2)\end{array}$ & 72.2 \\
\hline $\begin{array}{l}\text { Age - mean } \\
\text { (Min, Max) }\end{array}$ & $\begin{array}{l}51.3 \\
(38.2, \\
58.6)\end{array}$ & $\begin{array}{l}54.3 \\
(38.4 \\
57.5)\end{array}$ & $\begin{array}{l}49.7 \\
(48.0 \\
54.8)\end{array}$ & $\begin{array}{l}55.8 \\
(42.3, \\
58.6)\end{array}$ & 49.7 & $\begin{array}{l}47.8 \\
(38.6 \\
51.6)\end{array}$ & $\begin{array}{l}46.3 \\
(43.8 \\
46.8)\end{array}$ & 44.2 & $\begin{array}{l}42.6 \\
(40.1 \\
45.0)\end{array}$ & 38.2 \\
\hline $\begin{array}{l}\text { Migrant } \\
\text { background - } \\
\% \text { (Min, Max) }\end{array}$ & $\begin{array}{l}7.6 \\
(0.0 \\
22.8)\end{array}$ & $\begin{array}{l}19.3 \\
(3.5 \\
22.8)\end{array}$ & $\begin{array}{l}0.3 \\
(0.2 \\
0.3)\end{array}$ & $\begin{array}{l}10.9 \\
(0.9 \\
18.4)\end{array}$ & 0.0 & $\begin{array}{l}5.8 \\
(0.5 \\
12.5)\end{array}$ & $\begin{array}{l}0.6 \\
(0.0 \\
0.7)\end{array}$ & 0.0 & $\begin{array}{l}0.6 \\
(0.3 \\
1.0)\end{array}$ & 0.5 \\
\hline \multicolumn{11}{|l|}{$\begin{array}{l}\text { Living } \\
\text { situation - \% } \\
\text { (Min, Max) }\end{array}$} \\
\hline Alone & $\begin{array}{l}18.3 \\
(4.1, \\
31.0)\end{array}$ & $\begin{array}{l}20.9 \\
(6.5 \\
22.9)\end{array}$ & $\begin{array}{l}24.8 \\
(15.6 \\
27.9)\end{array}$ & $\begin{array}{l}24.7 \\
(12.4 \\
28.5)\end{array}$ & 5.3 & $\begin{array}{l}17.8 \\
(4.4, \\
31.0)\end{array}$ & $\begin{array}{l}11.0 \\
(5.0, \\
12.3)\end{array}$ & 6.5 & $\begin{array}{l}4.5 \\
(4.1 \\
5.0)\end{array}$ & 10.6 \\
\hline $\begin{array}{l}\text { With } \\
\text { others }\end{array}$ & $\begin{array}{l}76.8 \\
(65.1, \\
94.8)\end{array}$ & $\begin{array}{l}73.1 \\
(63.3 \\
80.3)\end{array}$ & $\begin{array}{l}72.3 \\
(69.0 \\
82.1)\end{array}$ & $\begin{array}{l}69.4 \\
(65.9 \\
87.2)\end{array}$ & 91.9 & $\begin{array}{l}79.9 \\
(65.1 \\
94.8)\end{array}$ & $\begin{array}{l}82.1 \\
(77.6 \\
83.0)\end{array}$ & 92.5 & $\begin{array}{l}88.0 \\
(87.2 \\
88.8)\end{array}$ & 88.9 \\
\hline $\ln _{\text {institution }}$ & $\begin{array}{l}3.3 \\
(0.0 \\
27.1)\end{array}$ & $\begin{array}{l}5.6 \\
(0.5 \\
27.1)\end{array}$ & $\begin{array}{l}1.2 \\
(1.0 \\
1.7)\end{array}$ & $\begin{array}{l}3.0 \\
(0, \\
3.4)\end{array}$ & 2.4 & $\begin{array}{l}1.4 \\
(0.5 \\
1.9)\end{array}$ & $\begin{array}{l}6.0 \\
(3.9 \\
15.9)\end{array}$ & 0.0 & $\begin{array}{l}6.0 \\
(4.7 \\
7.2)\end{array}$ & 0.5 \\
\hline
\end{tabular}

$\mathrm{SCl}$

characteristics

\begin{tabular}{|c|c|c|c|c|c|c|c|c|c|c|}
\hline $\begin{array}{l}\text { Tetraplegia - } \\
\% \text { (Min, Max) }\end{array}$ & $\begin{array}{l}36.4 \\
(10.0 \\
49.0)\end{array}$ & $\begin{array}{l}37.0 \\
(36.7 \\
38.4)^{\prime}\end{array}$ & $\begin{array}{l}41.7 \\
(39.3 \\
49.0)\end{array}$ & $\begin{array}{l}38.2 \\
(29.8 \\
46.9)\end{array}$ & 33.1 & $\begin{array}{l}31.1 \\
(25.7 \\
36.0)\end{array}$ & $\begin{array}{l}39.6 \\
(10.0 \\
45.7)\end{array}$ & 40.3 & $\begin{array}{l}27.5 \\
(25.6 \\
29.5)\end{array}$ & 30.6 \\
\hline $\begin{array}{l}\text { Incomplete } \\
\text { lesion - \% } \\
\text { (Min, Max) }\end{array}$ & $\begin{array}{l}60.4 \\
(25.2 \\
79.1)\end{array}$ & $\begin{array}{l}64.6 \\
(46.7 \\
71.4)\end{array}$ & $\begin{array}{l}40.3 \\
(35.8 \\
41.8)\end{array}$ & $\begin{array}{l}62.1 \\
(25.2, \\
79.0)\end{array}$ & 74.5 & $\begin{array}{l}55.8 \\
(53.5 \\
60.7)\end{array}$ & $\begin{array}{l}54.7 \\
(54.1 \\
57.7)\end{array}$ & 79.1 & $\begin{array}{l}56.8 \\
(54.7 \\
59.1)\end{array}$ & 67.1 \\
\hline $\begin{array}{l}\text { Nontraumatic } \\
\text { etiology - \% } \\
\text { (Min, Max) }\end{array}$ & $\begin{array}{l}19.0 \\
(0.0, \\
36.5)\end{array}$ & $\begin{array}{l}13.8 \\
(0.0, \\
16.3)\end{array}$ & $\begin{array}{l}8.3 \\
(7.8, \\
9.9)\end{array}$ & $\begin{array}{l}22.0 \\
(6.4, \\
36.5)\end{array}$ & 32.3 & $\begin{array}{l}21.4 \\
(14.0 \\
29.6)\end{array}$ & $\begin{array}{l}10.9 \\
(10.7 \\
11.9)^{\prime}\end{array}$ & 29.9 & $\begin{array}{l}14.1 \\
(13.8 \\
14.4)\end{array}$ & 16.2 \\
\hline $\begin{array}{l}\text { Years lived } \\
\text { with SCl - } \\
\text { mean (Min, } \\
\text { Max) }\end{array}$ & $\begin{array}{l}13.2 \\
(3.3 \\
20.0)\end{array}$ & $\begin{array}{l}16.0 \\
(10.3, \\
17.2)\end{array}$ & $\begin{array}{l}16.7 \\
(15.6 \\
20.0)\end{array}$ & $\begin{array}{l}14.8 \\
(8.4 \\
19.1)\end{array}$ & 4.5 & $\begin{array}{l}13.8 \\
(7.0, \\
18.1)\end{array}$ & $\begin{array}{l}13.3 \\
(11.0 \\
13.8)\end{array}$ & 3.3 & $\begin{array}{l}8.7 \\
(8.3 \\
9.2)\end{array}$ & 8.2 \\
\hline
\end{tabular}

a AU - Australia, BR - Brazil, CN - China, FR - France, DE - Germany, GR - Greece, ID - Indonesia, IT - Italy, JP - Japan, LT - Lithuania, MY - Malaysia, MA - Morocco, NL - Netherlands, NO - Norway, PL - Poland, RO - Romania, ZA - South Africa, KR - South Korea, ES - 
Spain, $\mathrm{CH}$ - Switzerland, TH - Thailand, US - USA

${ }^{\mathrm{b}}$ Healthcare experience score obtained after Rasch analysis

\section{Association between Utilization and Experience}

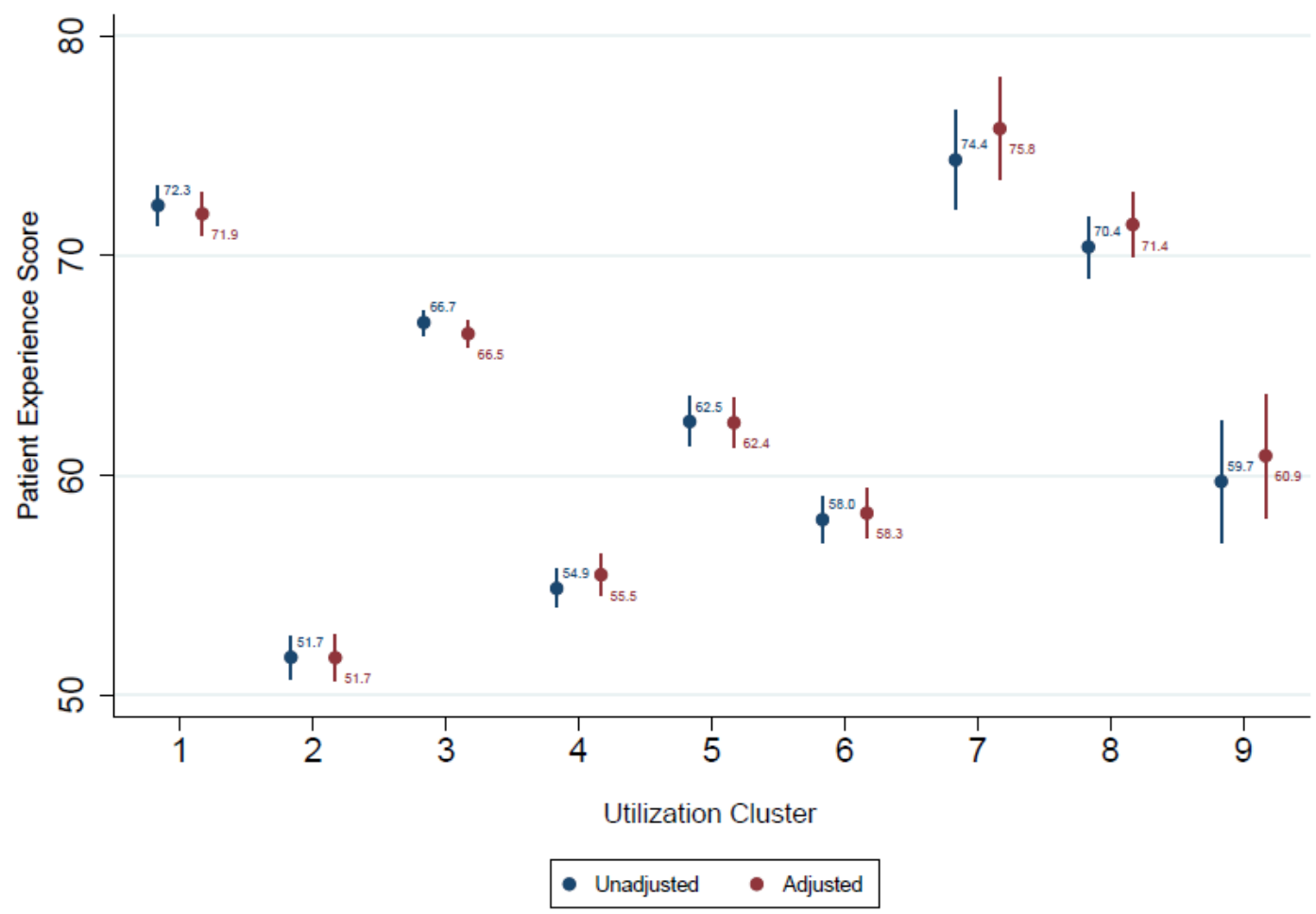

Figure 1

Association between Utilization and Experience Patient experience score range: 0-100. Cluster numbers and countries: 1 - Australia, South Africa, USA; 2 Japan, South Korea; 3 - Switzerland, Germany, Lithuania, Netherlands, Norway; 4 - China; 5 - France, Greece, Italy, Morocco, Spain; 6 - Indonesia, Poland; 7 Brazil; 8 - Malaysia, Thailand; 9 - Romania.

\section{Supplementary Files}

This is a list of supplementary files associated with this preprint. Click to download.

- Additionalfile1.docx 